\title{
OPEN Soticlestat, a novel cholesterol 24-hydroxylase inhibitor shows a therapeutic potential for neural hyperexcitation in mice
}

Toshiya Nishi ${ }^{1,3 凶}$, Shinichi Kondo ${ }^{1}$, Maki Miyamoto ${ }^{1}$, Sayuri Watanabe ${ }^{1}$, Shigeo Hasegawa ${ }^{1}$, Shigeru Kondo ${ }^{1}$, Jason Yano ${ }^{1}$, Etsurou Watanabe ${ }^{1}$, Tsuyoshi Ishi ${ }^{1}$, Masato Yoshikawa ${ }^{1}$, Haruhi Kamisaki Ando ${ }^{1}$, William Farnaby ${ }^{1}$, Shinji Fujimoto ${ }^{1}$, Eiji Sunahara ${ }^{1}$, Momoko Ohori ${ }^{1}$, Matthew J. During ${ }^{2}$, Takanobu Kuroita ${ }^{1}$ \& Tatsuki Koike ${ }^{1}$

Cholesterol 24-hydroxylase $(\mathrm{CH} 24 \mathrm{H})$ is a brain-specific enzyme that converts cholesterol into 24S-hydroxycholesterol, the primary mechanism of cholesterol catabolism in the brain. The therapeutic potential of $\mathrm{CH} 24 \mathrm{H}$ activation has been extensively investigated, whereas the effects of $\mathrm{CH} 24 \mathrm{H}$ inhibition remain poorly characterized. In this study, the therapeutic potential of $\mathrm{CH} 24 \mathrm{H}$ inhibition was investigated using a newly identified small molecule, soticlestat (TAK-935/OV935). The biodistribution and target engagement of soticlestat was assessed in mice. $\mathrm{CH} 24 \mathrm{H}-\mathrm{knockout}$ mice showed a substantially lower level of soticlestat distribution in the brain than wild-type controls. Furthermore, brain-slice autoradiography studies demonstrated the absence of $\left[{ }^{3} \mathrm{H}\right]$ soticlestat staining in $\mathrm{CH} 24 \mathrm{H}-k n o c k o u t$ mice compared with wild-type mice, indicating a specificity of soticlestat binding to $\mathrm{CH} 24 \mathrm{H}$. The pharmacodynamic effects of soticlestat were characterized in a transgenic mouse model carrying mutated human amyloid precursor protein and presenilin 1 (APP/PS1-Tg). These mice, with excitatory/inhibitory imbalance and short life-span, yielded a remarkable survival benefit when bred with $\mathrm{CH} 24 \mathrm{H}-$ knockout animals. Soticlestat lowered brain 24S-hydroxycholesterol in a dose-dependent manner and substantially reduced premature deaths of APP/PS1-Tg mice at a dose lowering brain $24 S$-hydroxycholesterol by approximately $50 \%$. Furthermore, microdialysis experiments showed that soticlestat can suppress potassium-evoked extracellular glutamate elevations in the hippocampus. Taken together, these data suggest that soticlestat-mediated inhibition of $\mathrm{CH} 24 \mathrm{H}$ may have therapeutic potential for diseases associated with neural hyperexcitation.

The brain is rich in cholesterol, accounting for nearly a quarter of the body's total cholesterol. Cholesterol plays fundamental roles in maintaining a variety of physiological functions in the brain, such as regulation of membrane potential and release of synaptic vesicles ${ }^{1-3}$. Regulation of cholesterol homeostasis in the brain differs from that in the periphery ${ }^{4}$. One such example is the formation of $24 S$-hydroxycholesterol, which is the dominant pathway of cholesterol catabolism in the brain $^{5,6}$. The excretion of $24 S$-hydroxycholesterol is unidirectional unlike 27-hydroxycholesterol, which can pass through the blood-brain barrier ${ }^{7}$. 24-hydroxylation of cholesterol is catalysed by CYP46A1 (also known as cholesterol 24-hydroxylase [CH24H]), with expression being largely restricted to neurons ${ }^{8-10}$. It is important to note that extracerebral formation of $24 S$-hydroxycholesterol was observed in mice and rats, although the protein expression level of $\mathrm{CH} 24 \mathrm{H}$ in liver was less than $1 \%$ of that in brain $^{11}$. Considering that $24 S$-hydroxycholesterol is detected in the circulation of $\mathrm{CH} 24 \mathrm{H}$-knockout $(\mathrm{KO})$ mice, 24-hydroxylation of cholesterol can occur through a $\mathrm{CH} 24 \mathrm{H}$-independent mechanism in mice. Nevertheless, in humans, most of the circulating $24 S$-hydroxycholesterol is derived from the brain ${ }^{12}$.

Known as a brain-specific enzyme, $\mathrm{CH} 24 \mathrm{H}$ has a potential role in neurological disorders and has been the focus of several genetic studies. For example, investigators have studied the association of polymorphisms of the $\mathrm{CH} 24 \mathrm{H}$ gene with Alzheimer's disease $(\mathrm{AD})^{10,13}$ and glaucoma ${ }^{14}$; however, no consensus has been established on

${ }^{1}$ Research, Takeda Pharmaceutical Company Limited, Fujisawa 251-8555, Japan. ${ }^{2}$ Ovid Therapeutics, 1460 Broadway, New York, NY 10036, USA. ${ }^{3}$ Takeda Pharmaceutical Company Limited, Cambridge, MA 02139, USA. ${ }^{\boxplus}$ email: toshiya.nishi@takeda.com 
the relationship of these polymorphisms with disease. Given that $\mathrm{CH} 24 \mathrm{H}$ catalyses the dominant mechanism of the excretion of cholesterol from the brain, its activation has been considered as a therapeutic strategy to stimulate brain cholesterol metabolism. For example, local overexpression of $\mathrm{CH} 24 \mathrm{H}$ by a viral vector is beneficial in experimental animal models of $\mathrm{AD}$ and Huntington's disease ${ }^{15-17}$. More recently, the reverse transcriptase inhibitor efavirenz has been characterized as a $\mathrm{CH} 24 \mathrm{H}$ activator for potential treatment for $\mathrm{AD}^{18-20}$. However, such interventional strategies may be limited by the potential toxicity of $24 S$-hydroxycholesterol, the enzymatic product of $\mathrm{CH} 24 \mathrm{H}$. Previously known as 'cerebrosterol', $24 S$-hydroxycholesterol has been shown to influence various biological functions, including facilitation of $\mathrm{N}$-methyl-d-aspartate (NMDA) signalling, inflammation, oxidative stress and necroptosis ${ }^{21-25}$, implying that lowering brain $24 S$-hydroxycholesterol levels could also be therapeutic when these factors are driving pathology.

Pharmacological inhibition of $\mathrm{CH} 24 \mathrm{H}$ can complement and expand on genetic studies to investigate the therapeutic potential of $24 S$-hydroxycholesterol lowering. Several molecules are known for $\mathrm{CH} 24 \mathrm{H}$ inhibitory activity $^{26}$; however, there have been few attempts to test the therapeutic potential of such agents, presumably owing to their non-specificity and pleiotropic activity. One of the earliest examples is voriconazole. This antifungal agent was originally developed as an ergosterol synthesis inhibitor ${ }^{27}$. Although voriconazole reportedly reduces brain $24 S$-hydroxycholesterol, its pharmacological effects are not purely attributable to $\mathrm{CH} 24 \mathrm{H}$ inhibition because the drug also interferes with extracerebral cholesterol metabolism. It is, therefore, important to identify a potent, highly-specific and brain-penetrable $\mathrm{CH} 24 \mathrm{H}$ inhibitor that merits preclinical and clinical investigations of the effects of perturbating brain cholesterol metabolism. Here, we describe soticlestat ([4-benzyl-4-hydroxypiperidin-1-yl] [2,4'-bipyridin-3-yl] methanone, TAK-935, also known as OV935) as a novel CH24H inhibitor. To investigate the pharmacological benefits of soticlestat, we employed a transgenic mouse model carrying human amyloid precursor protein and presenilin 1 (APP/PS1-Tg) ${ }^{28,29}$. Originally developed as an AD model, APP/PS1$\mathrm{Tg}$ is also known for excitatory/inhibitory imbalance and seizure-related sudden death ${ }^{30,31}$. Most importantly, it was shown that cross-breeding of APP/PS1-Tg mice with $\mathrm{CH} 24 \mathrm{H}$-deficient mice extended life-span regardless of zygosity ${ }^{32}$. The observation in conventional knockout mice, however, has left room for the argument that the survival benefit of $\mathrm{CH} 24 \mathrm{H}$ insufficiency is attributable to alteration of brain development. Employing a newly identified small-molecule inhibitor, we tested if the high mortality can be reversed by post-development intervention. The present study provides a rationale and supports the hypothesis that pharmacological inhibition of $\mathrm{CH} 24 \mathrm{H}$ may have therapeutic relevance to central nervous system (CNS) hyperexcitability.

\section{Results}

$\mathrm{CH} 24 \mathrm{H}$ inhibitory activity and in vitro/in vivo target engagement of soticlestat. Soticlestat (Supplementary Fig. S1) was discovered as a result of an iterative medicinal chemistry effort following highthroughput screening of an in vitro enzyme assay (Fig. 1A,B). Soticlestat inhibited the catalytic activity of human $\mathrm{CH} 24 \mathrm{H}$ in a concentration-dependent manner with a half-maximal inhibitory concentration $\left(\mathrm{IC}_{50}\right)$ of $4.5 \mathrm{nmol} / \mathrm{L}$. In our preliminary screening assays for major CNS drug targets and drug-metabolizing enzymes, soticlestat did not show notable activities at a concentration 10,000 times higher than the $\mathrm{IC}_{50}$ for $\mathrm{CH} 24 \mathrm{H}$ inhibition (Supplementary table S1 and S2).

Target engagement specificity was further examined via autoradiography using brain slices collected from wild-type (WT) and $\mathrm{CH} 24 \mathrm{H}$-deficient $\mathrm{KO}$ mice (Fig. 1C). The binding of $\left[{ }^{3} \mathrm{H}\right]$ soticlestat $(300 \mathrm{nmol} / \mathrm{L})$ showed a clear contrast between WT and $\mathrm{CH} 24 \mathrm{H}-\mathrm{KO}$ mice. At this concentration, soticlestat inhibitory activity on $\mathrm{CH} 24 \mathrm{H}$ is saturated (Fig. 1B). The data suggest that the molecule is highly specific for $\mathrm{CH} 24 \mathrm{H}$. In WT brain slices, the cerebral cortex, thalamus, midbrain and hypothalamus showed relatively stronger binding than the cerebellum, which appeared to be only weakly labelled, implying a relatively broad expression of the enzyme in the cerebrum. The localisation of $\left[{ }^{3} \mathrm{H}\right]$ soticlestat signals agrees with immunohistochemistry of $\mathrm{CH} 24 \mathrm{H}$ protein in mouse brain, further supporting the binding specificity to the target (Supplementary Fig. S2A). The lower binding of $\left[{ }^{3} \mathrm{H}\right]$ soticlestat to cerebellum is consistent with our preliminary assessment of regional levels of $24 S$-hydroxycholesterol, which found the highest levels in the striatum and the lowest in the cerebellum (Supplementary Fig. S2B). These observations also agree with a recent study indicating a low level of $24 S$-hydroxycholesterol in the cerebellum ${ }^{33}$, while an earlier immunohistochemistry study detected a relatively high level of $\mathrm{CH} 24 \mathrm{H}$ expression in Purkinje cells ${ }^{34}$. To further characterize the $\mathrm{CH} 24 \mathrm{H}$ binding specificity of soticlestat, biodistribution experiments were conducted in vivo, comparing $\mathrm{CH} 24 \mathrm{H}-\mathrm{KO}$ and WT mice following intravenous injection (Fig. 1D). The plasma concentrations of soticlestat $1 \mathrm{~h}$ after injection were similar between the two strains at $9.2 \pm 4.1 \mathrm{ng} / \mathrm{mL}$ and $11.9 \pm 2.8 \mathrm{ng} / \mathrm{mL}$ (mean \pm standard error of measurement [s.e.m.]) for WT and $\mathrm{CH} 24 \mathrm{H}-\mathrm{KO}$ mice, respectively. In the brain, soticlestat content in WT and $\mathrm{CH} 24 \mathrm{H}-\mathrm{KO}$ mice was notably different at $26.1 \pm 0.8 \mathrm{ng} / \mathrm{g}$ and $0.9 \pm 0.3 \mathrm{ng} / \mathrm{g}$ (mean \pm s.e.m.), respectively. These data collectively suggest that soticlestat has an adequately specific affinity to $\mathrm{CH} 24 \mathrm{H}$ that deserves further investigation of pharmacodynamics (PD).

Evaluation of pharmacodynamics (PD) of soticlestat in APP/PS1-Tg mice. The first study to demonstrate a therapeutic benefit of $\mathrm{CH} 24 \mathrm{H}$ inhibition was reported by Halford et al. ${ }^{32}$. In the study, both heterozygous and homozygous $\mathrm{CH} 24 \mathrm{H} \mathrm{KO}$ remarkably extended the life-span of APP/PS1-Tg mice, while not affecting the amyloid pathology. Based on this study, we employed a strain of APP/PS1-Tg mice with a different PS-1 mutation $^{28,29}$. When brain levels of $24 S$-hydroxycholesterol were evaluated, APP/PS1-Tg mice did not show notably higher levels of brain 24S-hydroxycholesterol content than WT animals of the same background strain (Fig. 2A). To test if soticlestat can reduce 24S-hydroxycholesterol in the brain, APP/PS1-Tg mice were orally treated with the drug for different time periods as indicated in Fig. 2B. A hysteresis was observed in soticlestat effects on $24 S$-hydroxycholesterol with a temporal pattern that was delayed compared with the pharmacokinetics (PK) data (Fig. 2B and Supplementary Fig. S3A). In a single-dose experiment, soticlestat took 24 h to 
A

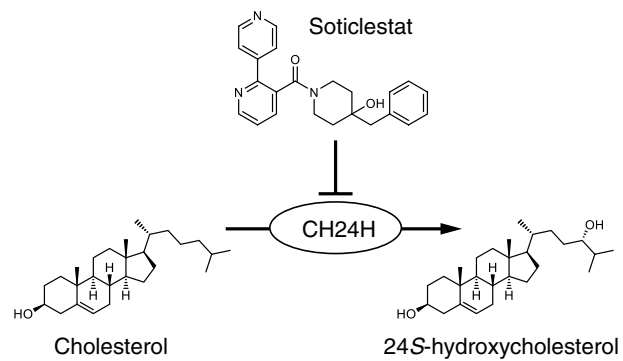

C

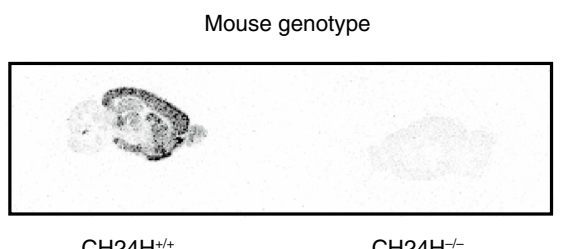

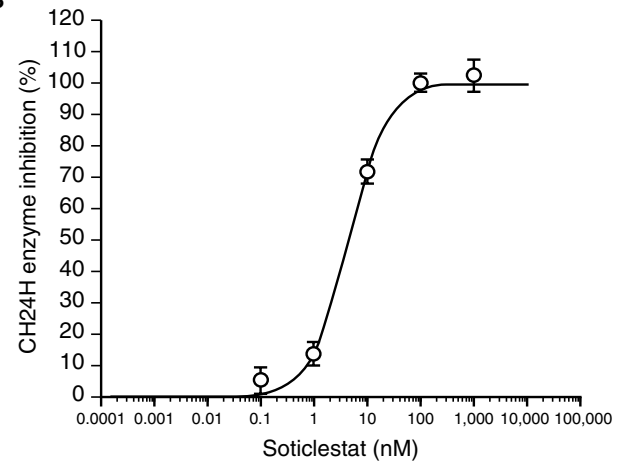

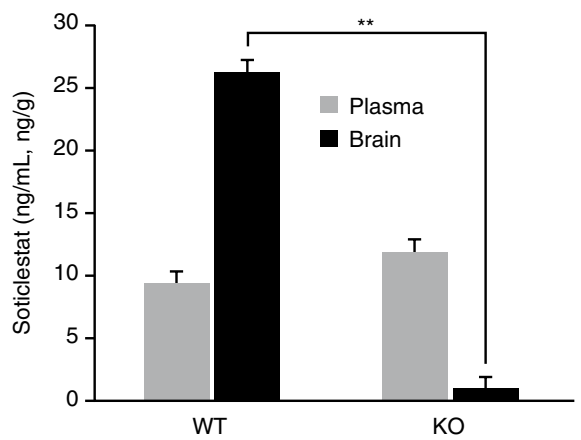

Figure 1. $\mathrm{CH} 24 \mathrm{H}$ enzyme inhibition by soticlestat and its target engagement. (A) The chemical structure of soticlestat, (4-benzyl-4-hydroxypiperidin-1-yl)(2,4'-bipyridin-3-yl) methanone. (B) Human CH24H enzyme inhibition by soticlestat. (C) Autoradiographic image of $300 \mathrm{nmol} / \mathrm{L}\left[{ }^{3} \mathrm{H}\right]$ soticlestat on brain slices from $\mathrm{CH} 24 \mathrm{H}-\mathrm{KO}$ and WT control mice $(\mathrm{n}=3)$. Representative images are shown. (D) Plasma and brain levels of soticlestat in $\mathrm{CH} 24 \mathrm{H}-\mathrm{KO}$ and WT mice $1 \mathrm{~h}$ after intravenous injection of soticlestat $(0.3 \mathrm{mg} / \mathrm{kg})$. Data are mean \pm s.e.m. $(\mathrm{n}=3) .{ }^{* *} \mathrm{P}<0.01$ (Student's t-test). $\mathrm{CH} 24 \mathrm{H}$, cholesterol 24-hydroxylase; KO, knockout; s.e.m., standard error of measurement; WT, wild-type.

reach maximum levels of brain 24S-hydroxycholesterol lowering (Fig. 2B). Despite a small number of samples, an association was found between PK and PD (Supplementary Fig. S3B, $r=-0.961$ ). Soticlestat PD effects on brain $24 S$-hydroxycholesterol reached an apparent steady state after repetitive treatments for 3 days. The dose dependency of 24S-hydroxycholesterol lowering was further assessed in APP/PS1-Tg mice after 3 days of soticlestat treatment (Fig. 2C). Soticlestat showed a dose-dependent reduction of 24S-hydroxycholesterol, reaching a decrease of about $50 \%$ at $10 \mathrm{mg} / \mathrm{kg}$. Presumably owing to limited bioavailability in mice, $24 S$-hydroxycholesterol lowering effects of soticlestat almost reached a plateau at the dose of $10 \mathrm{mg} / \mathrm{kg}$ and higher with oral gavage (Supplementary Fig. S4). This dose was selected as a treatment condition of soticlestat that yields similar levels of enzyme inhibition to that found in heterozygous $\mathrm{CH} 24 \mathrm{H} \mathrm{KO}^{5}$. The dose dependency of $24 S$-hydroxycholesterol lowering by soticlestat did not show any noticeable difference in the WT control animals (Supplementary Fig. S5). The potential effects of soticlestat on AD pathology were examined in pilot experiments using 3-monthold APP/PS1-Tg mice. No noticeable effects of soticlestat were observed on amyloid pathology (Supplementary Fig. S6), while a trend was observed on the improvement in working memory deficits in the Y-maze test (Supplementary Fig. S7).

Originally developed as an AD mouse model, APP/PS1-Tg mice have also been recognized as a model of excitatory/inhibitory imbalance, including seizure-related sudden death ${ }^{30,31,35-37}$. The strain kept in our facility showed approximate $50 \%$ mortality over the first 3 months after birth. To test the potential effect on survival, soticlestat intervention $(10 \mathrm{mg} / \mathrm{kg}$ orally [PO], once daily [QD]) was initiated from 7 weeks of age and maintained for 8 weeks. A significant difference was found in the survival curve between the vehicle arm and the soticlestat treatment arm (Fig. 2D). A total of 14 out of 30 mice died in the control group, while 2 out of 30 mice died in the soticlestat group throughout the intervention period. The hazard ratio of death was 5.849 in the vehicle-treated arm compared with the soticlestat arm. The result indicated that soticlestat has a robust pro-survival benefit in the APP/PS1-Tg model in agreement with the earlier study done in $\mathrm{CH} 24 \mathrm{H}-\mathrm{KO}$ mice ${ }^{32}$.

Interestingly, enhanced cholesterol 24-hydroxylation reportedly decreases astrocytic glutamate sequestration $^{38}$, suggesting a potential role of $\mathrm{CH} 24 \mathrm{H}$ in an impaired glutamate uptake system in AD. The APP/ PS1-Tg model is also recognized for an epileptic phenotype, as well as for impairment of extracellular potassium homeostasis ${ }^{30,37}$. To unmask the hyperexcitability phenotype, $\mathrm{KCl}$ was infused through a microdialysis cannula into the hippocampus of freely moving awake animals ${ }^{39}$. With $100 \mathrm{mM} \mathrm{KCl}$ perfused, 7 out of $11 \mathrm{APP} /$ PS1-Tg mice developed lethal seizures, while no obvious behavioural changes were found in WT mice. In pilot experiments, a continuous infusion of $\mathrm{KCl}$ led to $100 \%$ mortality in APP/PS1-Tg mice unless tetrodotoxin was 
A

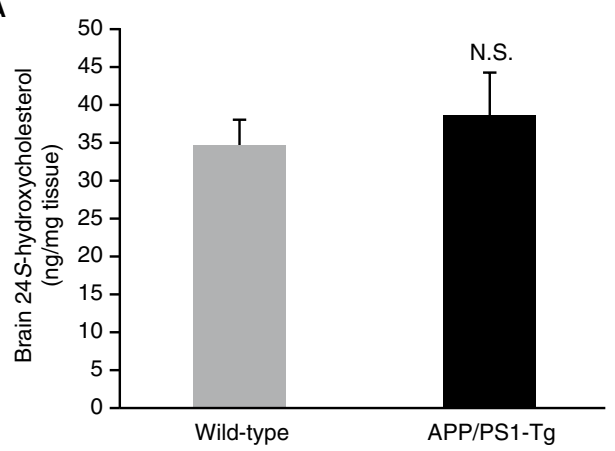

C

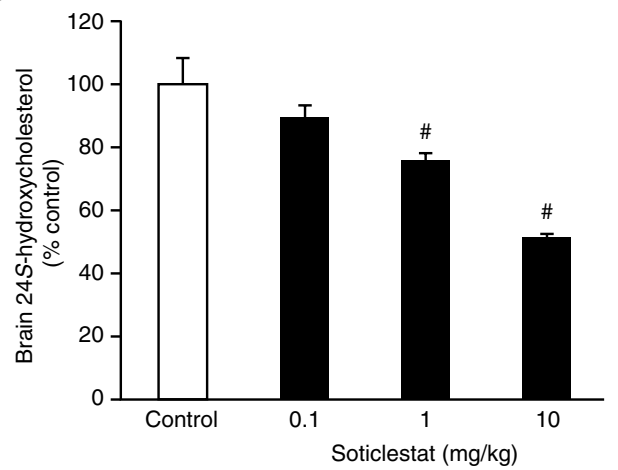

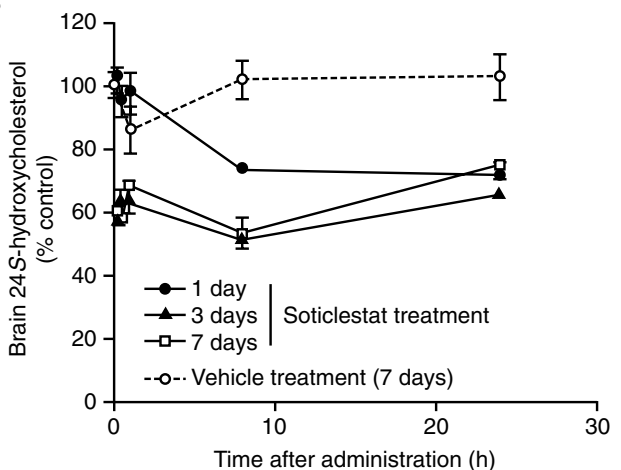

D

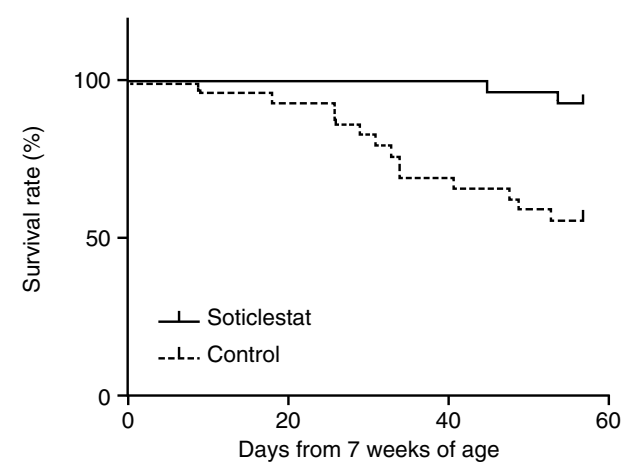

Figure 2. 24S-hydroxycholesterol lowering effects of soticlestat and survival benefits in APP/PS1-Tg mice. (A) Baseline brain 24S-hydroxycholesterol levels were compared between APP/PS1-Tg and its WT control at the age of 7 weeks. Data are mean \pm s.e.m. $(n=4)$. (B) Time course of brain 24S-hydroxycholesterol lowering in APP/ PS1-Tg mice by soticlestat treatment for 1,3 and 7 days $(10 \mathrm{mg} / \mathrm{kg}$ PO, QD). Vehicle ( $0.5 \%$ methyl cellulose) was administered for 7 days. Data are mean \pm s.d. $(n=3)$. N.S.: not significant (Student's t-test) (C) Dose-dependent reduction of brain 24S-hydroxycholesterol in APP/PS1-Tg after 3 days of repetitive soticlestat oral treatment. ${ }^{\#} P<0.025$ (one-tailed Williams test). Data are mean \pm s.e.m. $(n=4)$. (D) Kaplan-Meier curves of the survival rate of APP/PS1-Tg mice from 7 weeks of age $(\mathrm{n}=30)$. Mice were treated with vehicle and soticlestat $(10 \mathrm{mg} / \mathrm{kg} P O$, QD) over 8 weeks. Statistical significance was assessed by the log-rank test $(P<0.001)$. APP/PS1-Tg, transgenic mouse model carrying mutated human amyloid precursor protein and presenilin 1; PO, orally; QD, once daily; s.d., standard deviation; s.e.m., standard error of measurement; WT, wild-type.

infused to antagonize the KCl-induced depolarization (Fig. 3A). In contrast, no deaths were observed in WT mice. To control the mortality and to quantify the levels of extracellular glutamate elevation, experiments were terminated after $60 \mathrm{~min}$ of $\mathrm{KCl}$ perfusion. Glutamate levels in the WT and APP/PS1-Tg mice reached 4.0 \pm 1.2 and $23.0 \pm 4.9$ (mean \pm s.e.m.) times baseline levels, respectively (Fig. 3B). The data suggested the susceptibility of APP/PS1-Tg mice to catastrophic depolarization events. To assess the potential effects of soticlestat on the hippocampal hyperexcitability of the model, APP/PS1-Tg mice were treated with soticlestat for 2 weeks $(10 \mathrm{mg} /$ $\mathrm{kg}$ PO, QD) prior to undergoing microdialysis. It was found that the elevation of extracellular glutamate was greatly suppressed by soticlestat (Fig. 3C,D). Following the initiation of $\mathrm{KCl}$ perfusion, seizure-like behaviours became apparent in $50 \%$ of the vehicle-treated control mice accompanied by markedly elevated glutamate levels, whereas soticlestat-treated animals showed few behavioural abnormalities. Extracellular glutamate levels peaked at $28.9 \pm 8.7$ and $1.6 \pm 0.4$ (mean \pm s.e.m.) times baseline levels for control and soticlestat groups, respectively. Meanwhile, soticlestat treatment did not affect baseline glutamate levels before $\mathrm{KCl}$ perfusion (Fig. 3E; $0.33 \pm 0.04 \mu \mathrm{mol} / \mathrm{L}$ and $0.33 \pm 0.04 \mu \mathrm{mol} / \mathrm{L}$ for the control group and soticlestat group, respectively; mean \pm s.e.m). In a separate experiment, DL-threo- $\beta$-benzyloxyaspartate (TBOA), an inhibitor of astrocytic glutamate uptake, was used to determine the role of glutamate transporters in the observed increase in extracellular glutamate. In the presence of TBOA $(10 \mu \mathrm{mol} / \mathrm{L})$, soticlestat had no effect on extracellular glutamate (Supplementary Fig. S8). It was also reported that glutamate toxicity can induce $\mathrm{CH} 24 \mathrm{H}$ translocation from endoplasmic reticulum to the plasma membrane, thereby causing cholesterol $\operatorname{loss}^{40}$, which could apply to the APP/PS1-Tg model. However, loss of cholesterol was not found in a detergent resistant membrane component extracted from APP/PS1-Tg brain compared wild-type animals (Supplementary Fig. S9). It was also shown that soticlestat treatment had no considerable impact on the global brain cholesterol levels (Supplementary Fig. S10). Given the intricacy of homeostasis $^{41}$, however, it is possible that impacts of $\mathrm{CH} 24 \mathrm{H}$ inhibition of cholesterol levels can vary across different brain regions.

Indiscriminate dampening effects on neural excitation may result in adverse pharmacological phenotypes such as sedation. To support clinical development in terms of preclinical safety, naïve ICR mice were 
A

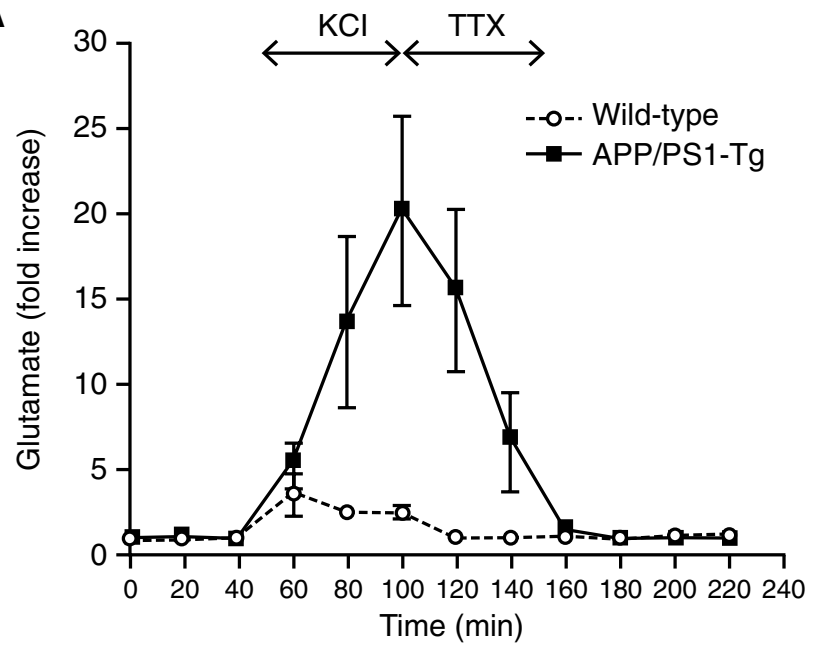

C

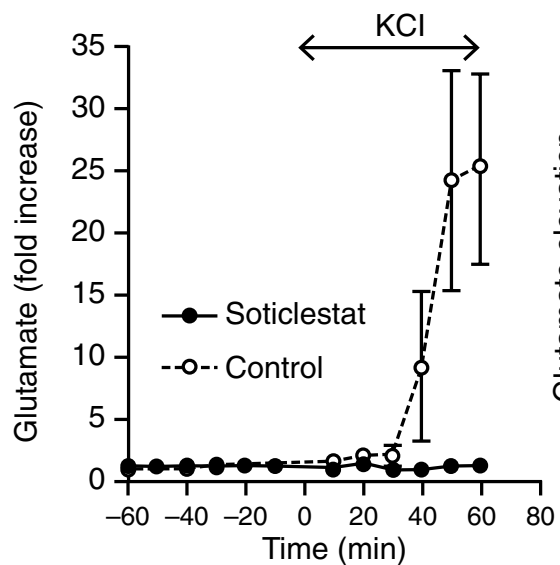

D

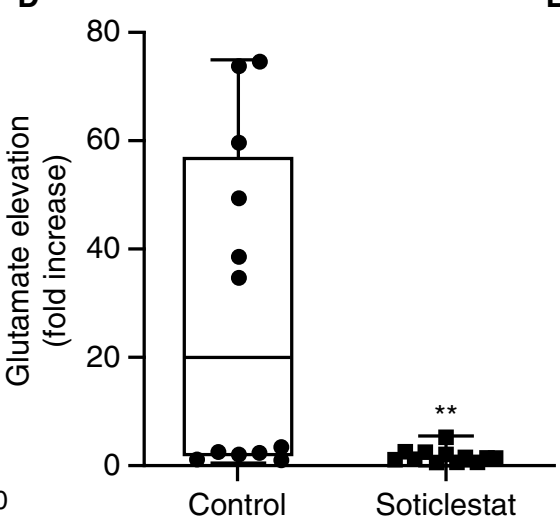

B

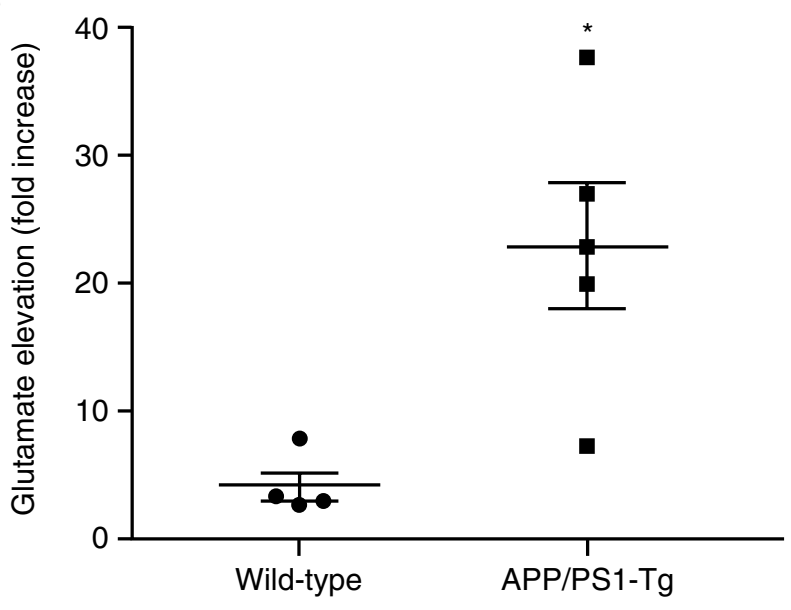

Figure 3. Soticlestat reversed the susceptibility of APP/PS1-Tg mice to potassium-induced glutamate spillover in the hippocampus. (A) Elevations in extracellular glutamate in the hippocampus of APP/PS1-Tg and WT mice under $100 \mathrm{mM} \mathrm{KCl}$ perfusion, followed by $10 \mu \mathrm{M}$ TTX. Data are mean \pm s.e.m. $(\mathrm{n}=4-5)$. (B) The maximum elevations of extracellular glutamate levels during KCl perfusion in the WT and APP/PS1-Tg mice. Data are mean \pm s.e.m. $(\mathrm{n}=4-5) .{ }^{\star} P<0.05$ (Student's $t$-test). (C) Effects of soticlestat $(10 \mathrm{mg} / \mathrm{kg}$ PO, $\mathrm{QD})$ on the extracellular level of glutamate before and during hippocampal $\mathrm{KCl}$ perfusion following 2-week treatment in APP/PS1-Tg mice. The time when $\mathrm{KCl}$ perfusion started was defined as $0 \mathrm{~min}$ in the figure. Data are mean \pm s.e.m. $(n=12)$. (D) Effects on the elevations in glutamate from baseline for the $60 \mathrm{~min} \mathrm{KCl}$ perfusion in APP/PS1-Tg mice. The analysis was based on the time-course data shown in (C). Data are mean \pm s.e.m. $(\mathrm{n}=12) .{ }^{*} \mathrm{P}<0.01$ (Student's $t$-test) $(\mathbf{E})$ Effects on the baseline levels of extracellular glutamate collected during the $60 \mathrm{~min}$ prior to $\mathrm{KCl}$ perfusion. The analysis was based on the time-course data shown in (C). Data are mean \pm s.e.m. $(n=12)$. APP/PS1-Tg, transgenic mouse model carrying mutated human amyloid precursor protein and presenilin 1; N.S. not significant; PO, orally; QD, once daily; s.e.m., standard error of measurement; TTX, tetrodotoxin; WT, wild-type.

continuously infused with soticlestat for 2 weeks $(10 \mathrm{mg} / \mathrm{kg}$, subcutaneous [SC] infusion) to yield a maximum level of $24 S$-hydroxycholesterol lowering and underwent motor phenotype assessments. Under the treatment condition, soticlestat reduced brain $24 S$-hydroxycholesterol by around $96 \%$, while no notable effects on motor coordination and spontaneous locomotor activity were observed (Supplementary Fig. S11). These data collectively suggest that $\mathrm{CH} 24 \mathrm{H}$ inhibition can tip the neural excitatory/inhibitory balance without indiscriminately dampening neural excitation.

\section{Discussion}

The brain-specific, cholesterol-catabolic enzyme $\mathrm{CH} 24 \mathrm{H}$ has gained increased attention as a potential drug target $^{18,19}$. Clarifying hitherto unproven therapeutic benefits of $\mathrm{CH} 24 \mathrm{H}$ inhibitor ${ }^{26}$, the present study provides new insights into the therapeutic relevance of pharmacological modulation of this enzyme ${ }^{18-20,42}$. The data shown here suggest that $24 S$-hydroxycholesterol lowering by soticlestat has therapeutic potential in diseases with underlying excitatory/inhibitory imbalance in the brain. The assessment of soticlestat safety and 'absorption, distribution, metabolism and excretion' profile has already led to clinical translation ${ }^{43}$. 
To identify a disease condition relevant to $\mathrm{CH} 24 \mathrm{H}$ inhibition, we employed the APP/PS1-Tg model, following the previous report that suggested a potential survival benefit of conventional $\mathrm{CH} 24 \mathrm{H} \mathrm{KO}{ }^{32}$. Chemical inhibition of a protein does not necessarily produce a phenotype aligned with conventional $\mathrm{KO}$ of the gene. In this sense, it might be emphasized that soticlestat intervention showed a survival benefit in 7-week-old APP/PS1-Tg mice. One obvious difference from conventional $\mathrm{KO}$ is that $\mathrm{CH} 24 \mathrm{H}$ was postnatally inhibited by soticlestat in our experiments, indicating that the therapeutic window is not necessarily confined to the prenatal or perinatal period of APP/PS1-Tg mice. It is intriguing to contemplate that activity of cholesterol 24-hydroxylation matters to the balance between life and death depending on the state of brain. Among known mortality factors, neural excitatory/inhibitory balance was highlighted as being important in a recent study of RE1-silencing transcription factor ${ }^{44}$. We are tempted to speculate that the survival benefit of soticlestat is also related to restoration of excitatory/inhibitory imbalance. Soticlestat suppressed the potassium-evoked glutamate elevation in APP/PS1Tg mice (Fig. 3C,D). Interestingly, its effects on glutamate were almost completely abolished by inhibition of glutamate reuptake by TBOA (Supplementary Fig. S8). Interpretation of the pharmacological experiment with TBOA is challenging; however, the data suggest that $\mathrm{CH} 24 \mathrm{H}$ inhibition is likely to affect astrocytic function as well as neuronal function. As mentioned earlier, cholesterol 24-hydroxylation in astrocytes can impair the glutamate reuptake function ${ }^{38}$. Furthermore, $\mathrm{Na}^{+} / \mathrm{K}^{+}$adenosine triphosphatase activity is impaired in the APP/ PS1-Tg model ${ }^{30}$, which is one of the astrocytic risk factors for sudden unexpected death in epilepsy ${ }^{45}$. Given the importance of potassium homeostasis as a risk factor for seizure-related death ${ }^{46}$, the potential involvement of $\mathrm{CH} 24 \mathrm{H}$ enzyme activity in the regulation of release and/or clearance of glutamate and/or potassium is an intriguing hypothesis to pursue.

To focus on the mortality-related phenotypes of APP/PS1-Tg mice, soticlestat was characterized mostly in young animals, instead of in aged animals associated with AD-related pathologies, to circumvent a population bias due to the high mortality. Nevertheless, it may be worthwhile briefly describing our preliminary experiments assessing a potential effect of soticlestat on cognitive functions in APP/PS1-Tg mice. One of the reported phenotypes of $\mathrm{CH} 24 \mathrm{H}-\mathrm{KO}$ mice is an impairment in learning ${ }^{47}$. Conversely, it has been reported that activation of $\mathrm{CH} 24 \mathrm{H}$ has pro-cognitive potential ${ }^{20,48}$. Three-month-old APP/PS1-Tg animals were treated with soticlestat and underwent the Y-maze test. Although a pharmacological experiment in 3-month-old APP/PS1-Tg mice does include a survival bias, our preliminary data, to the contrary, showed an apparent trend on the improvement in working memory (Supplementary Fig. S7). This observation may disagree with the cognitive benefits of efavirenz, a reverse transcriptase inhibitor known for $\mathrm{CH} 24 \mathrm{H}$ activation ${ }^{20,48}$. It should be noted that the effects of efavirenz on cognition are apparently associated with improvement in amyloid pathology. In our pilot experiments, however, soticlestat treatment had no notable impact on the amyloid pathology of APP/PS1-Tg mice (Supplementary Fig. S6). The lack of effects on amyloid pathology is also consistent with the phenotype of $\mathrm{CH} 24 \mathrm{H} \mathrm{KO}^{32}$. The improving trend of cognition seen in soticlestat could be explained by other mechanisms such as modulation of the excitatory/inhibitory balance.

One of the rationales for pharmacological activation of $\mathrm{CH} 24 \mathrm{H}$ is acceleration of brain cholesterol turn-over, which is expected to be beneficial for some neurodegenerative diseases ${ }^{15,20,49}$; however, this hypothesis may not be readily generalizable to other diseases. Firstly, acceleration of cholesterol 24-hydroxylation can disrupt the integrity of membrane $\mathrm{e}^{50}$, thereby possibly disturbing physiological functions of neurons $\mathrm{s}^{1-3}$. Secondly, $\mathrm{CH} 24 \mathrm{H}$ activation leads to upregulation of cholesterol biosynthesis, an energy-demanding process that consumes $18 \mathrm{~mol}$ of acetyl coenzyme A, $18 \mathrm{~mol}$ of adenosine triphosphate and $29 \mathrm{~mol}$ of nicotinamide adenine dinucleotide phosphate to produce $1 \mathrm{~mol}$ of cholesterol ${ }^{51}$. As the brain is an organ of high-energy demand and $100 \%$ selfsufficiency in cholesterol production, activation of this costly mechanism may add an extra burden on the brain $^{52}$. Further studies are needed to understand whether activation or inhibition of $\mathrm{CH} 24 \mathrm{H}$ can be therapeutic for each disease of interest. Future studies are planned to clarify whether or not, and how $\mathrm{CH} 24 \mathrm{H}$ inhibition can modulate cholesterol homeostasis in the brain. We propose that $24 S$-hydroxycholesterol lowering can be a therapeutic approach when this oxysterol is driving such pathology as inflammation, oxidative stress and excitatory/inhibitory imbalance ${ }^{24,25,53}$. Soticlestat is being tested in clinical trials for the treatment of epilepsy. In a separate study, soticlestat has been shown to ameliorate seizure progression in correlation with lowering of brain $24 S$-hydroxycholesterol in a mouse model of epilepsy $(\mathrm{r}=-0.682 ; P<0.05 \text {, Pearson correlation coefficient })^{43}$. The full set of data will be published elsewhere.

Finally, it is interesting to note that $\mathrm{CH} 24 \mathrm{H}$ knockdown can be neurotoxic in other animal models ${ }^{16,54}$. The hypothesis is, however, based on a viral vector-mediated RNA interference introduced locally in the hippocampus. Given the intricate interrelationship of neural circuits, it is possible that a regional somatic cell $\mathrm{CH} 24 \mathrm{H}$ knockdown, with uncertain specificity and using viral vectors with a known neuronal tropism, produces a result different from a pharmacological inhibition of the enzyme across all cell types and in the entire brain. Importantly, a nearly full inhibition of $\mathrm{CH} 24 \mathrm{H}$ by soticlestat did not cause notable abnormalities in motor coordination and spontaneous locomotor activities (Supplementary Fig. S11). In fact, hyperlocomotion is a typical behavioural phenotype of NMDA receptor (NMDAR) blocker ${ }^{55}$. Reduction of brain $24 S$-hydroxycholesterol, known as a potentiator NMDAR, may produce a similar phenotype, but this was not the case in our observation. As a matter of fact, the brain level of $24 S$-hydroxycholesterol is estimated at around $25 \mu \mathrm{M}$ across mammalian species, 20-fold higher than the reported half-maximal effective concentration on $\mathrm{NMDAR}^{21}$. Therefore, it is not surprising that even aggressive $\mathrm{CH} 24 \mathrm{H}$ inhibition by soticlestat does not disturb the baseline NMDAR functions.

In summary, the experiments conducted in this study collectively demonstrate the therapeutic potential of soticlestat. Considering the in vitro and in vivo assessment of soticlestat target engagement, it can be concluded that $\mathrm{CH} 24 \mathrm{H}$ inhibitor has a therapeutic potential that merits further investigation, not only in the clinical setting, but also as a basic research tool to shed light on the biological implications of $24 S$-hydroxycholesterol. 


\begin{abstract}
Methods
Measurement of $\mathrm{CH} 24 \mathrm{H}$ inhibitory activity. $\mathrm{CH} 24 \mathrm{H}$ enzyme was expressed by transducing the fulllength $\mathrm{CH} 24 \mathrm{H}$ gene (NCBI Accession Number BC022539) into FreeStyle 293-F cells (Invitrogen, Carlsbad, CA, USA). A CH24H lysate product was prepared from supernatant isolated by centrifugation of the homogenate. Catalytic activity of the $\mathrm{CH} 24 \mathrm{H}$ enzyme was measured using thin-layer chromatography (TLC). To evaluate the inhibitory activity, $2 \mu \mathrm{L}$ of serial diluted compounds were incubated with $3 \mu \mathrm{L}$ of $\mathrm{CH} 24 \mathrm{H}$ enzyme in assay buffer $(50 \mathrm{mM}$ potassium phosphate buffer [pH 7.4]) supplemented with $0.1 \%$ bovine serum albumin (BSA) and cOmplete EDTA-free tablets (Roche, Basel, Switzerland) for about $15 \mathrm{~min}$ at room temperature. The final concentration of dimethyl sulfoxide (DMSO) in the assay was $0.2 \%$ when the compound was tested in duplicate in 384-well plates. The reaction was started with the addition of $5 \mu \mathrm{L}$ of substrate $\left[{ }^{14} \mathrm{C}\right]$ cholesterol (PerkinElmer, Foster City, CA, USA, NEC018250UC) at a final concentration of $15 \mu \mathrm{M}$, which was dissolved in assay buffer containing $2 \mathrm{mM} \beta$-NADPH. After $5 \mathrm{~h}$ of incubation at $37^{\circ} \mathrm{C}, 35 \mu \mathrm{L}$ of chloroform:ethanol (1:2 v/v) was added to terminate the $\mathrm{CH} 24 \mathrm{H}$ reaction. After mixing, $25 \mu \mathrm{L}$ of distilled water containing $0.0024 \%$ trypan blue was added to the mixture. Based on the Bligh and Dyer total lipid extraction method, $4.5 \mu \mathrm{L}$ of the lower layer was spotted on the TLC plate (Silica Gel $60 \mathrm{~F}_{254}$, Merck, Darmstadt, Germany). The TLC plates were developed using ethyl acetate:toluene (2:3 v/v) and visualized by the ImageQuant TL software version 8.1 (GE Healthcare Ltd, Chalfont St Giles, UK) and analysed by the Multi Gauge software version 2.3 (Fujifilm Corporation, Tokyo, Japan). The band at Rf 0.53 was identified as $24 S$-hydroxycholesterol by LC/MS/MS and quantified by the analyser.
\end{abstract}

In vitro autoradiography in $\mathrm{CH} 24 \mathrm{H}$ WT and $\mathrm{KO}$ mouse brain sections. Twenty-seven-week-old male $\mathrm{CH} 24 \mathrm{H}$ WT and KO mice were euthanized by decapitation. The brains were rapidly removed and slowly frozen by immersion into an isopentane-dry ice bath. The frozen brains were stored in a deep freezer. Twenty micrometre-thick sagittal or coronal sections were cut on a cryostat (Leica Microsystems, Wetzlar, Germany) and thaw-mounted onto glass slides. The mouse sagittal sections were prepared from within 1.1-1.2 mm lateral to the midline (coordinates taken from the Franklin and Paxinos mouse brain atlas ${ }^{56}$ ). Sagittal sections prepared from $\mathrm{CH} 24 \mathrm{H}$ WT and $\mathrm{KO}$ mouse brains (3 mice in each genotype) on glass slides were warmed to room temperature. The sections were preincubated twice for $5 \mathrm{~min}$ at room temperature in preincubation buffer $(50 \mathrm{mmol} / \mathrm{L}$ of Tris- $\mathrm{HCl} \mathrm{pH} \mathrm{7.5,} 1.7 \mathrm{mmol} / \mathrm{L}$ of EDTA, $6 \mathrm{mmol} / \mathrm{L}$ of $\mathrm{MgCl}_{2}, 120 \mathrm{mmol} / \mathrm{L}$ of $\mathrm{NaCl}$, and $0.1 \% \mathrm{BSA}$ ). The sections were treated with $300 \mathrm{nmol} / \mathrm{L}$ of $\left[{ }^{3} \mathrm{H}\right]$ soticlestat in binding buffer (preincubation buffer containing $0.03 \%$ Triton X-100) for $4 \mathrm{~h}$ at room temperature. The sections were rinsed twice for $5 \mathrm{~min}$ at $4{ }^{\circ} \mathrm{C}$ in preincubation buffer and then rapidly rinsed in ice-cold distilled water. The sections were dried overnight at room temperature and exposed to imaging plates BAS-IP TR 2040 E (GE Healthcare Ltd, Chalfont St Giles, UK) for 7 days. The imaging plates were analysed using an image analyser FLA7000 (Fujifilm, Tokyo, Japan) and the ImageQuant TL software version 8.1 (GE Healthcare Ltd, Chalfont St Giles, UK).

Preparation of soticlestat. For oral administration, soticlestat was suspended in $0.5 \%(\mathrm{w} / \mathrm{v})$ methyl cellulose solution (Methyl Cellulose 50cp, Wako Pure Chemical Industries, Tokyo, Japan), and the prepared drug suspension was administered QD to mice at the volume of $10 \mathrm{~mL} / \mathrm{kg}$. SC infusion was employed to maximise the pharmacodynamics of soticlestat. Soticlestat was dissolved in DMSO and mixed with an equal volume of polyethylene glycol 400 (PEG 400). Osmotic pumps (Model 2004, Durect, Cupertino, CA, USA) filled with the prepared drug solution were implanted SC on the backs of the mice under anaesthesia.

Measurement of soticlestat exposure levels in plasma and brain. Plasma and brain were collected at the indicated time points to determine the exposure level of soticlestat following single and chronic administration. Whole blood was collected from the inferior vena cava with heparin. To collect brain samples, cerebellum was removed. The collected brain was homogenized with saline for subsequent procedures. The aliquots of plasma and the brain homogenate were mixed with acetonitrile containing deuterated soticlestat analogue as internal standard and then centrifuged. The supernatants were diluted with solvents for liquid chromatographytandem mass spectrometry (LC-MS/MS) (mobile phase A: $10 \mathrm{mM}$ of ammonium formate:formic acid [100:0.2 $\mathrm{v} / \mathrm{v}]$; mobile phase B: acetonitrile:formic acid [100:0.2 v/v]). The diluted solutions $(1-10 \mu \mathrm{L})$ were injected into LC-MS/MS solvent (API 5000, AB SCIEX, Foster City, CA, USA) that was equipped with Shimadzu Shim-pack XR-ODS $(2.2 \mu \mathrm{m}, 2.0 \times 30 \mathrm{~mm})\left(\right.$ Shimadzu, Kyoto, Japan) maintained at $50^{\circ} \mathrm{C}$. The chromatographic separation was performed with a gradient elution containing two mobile phases, $\mathrm{A}$ and $\mathrm{B}$, at a flow rate of $0.7 \mathrm{~mL} / \mathrm{min}$. Mobile phase B was held at 5\% for $0.2 \mathrm{~min}$ and increased linearly to $99 \%$ for $1.1 \mathrm{~min}$. After phase B was held at $99 \%$ for another $0.7 \mathrm{~min}$, it was brought back to $5 \%$ in $0.01 \mathrm{~min}$, followed by re-equilibration for $0.59 \mathrm{~min}$. The total cycle time for one injection was $2.6 \mathrm{~min}$. Compounds were detected using a multiple reaction monitoring mode using this transition: soticlestat $\mathrm{m} / \mathrm{z} 374.3$ ([4-benzyl-4-hydroxypiperidin-1-yl][2,4'-bipyridin3-yl] methanone) $\rightarrow 155.2$ /183.1 ([2,4'-bipyridin-3-yl]methanone moiety, Supplementary Fig. S12), soticlestat analogue $\mathrm{m} / \mathrm{z} 379.4 \rightarrow 155.2 / 183.1$ ([2,4'-bipyridin-3-yl]methanone moiety). Analyst Software version 1.4 .2 (SCIEX, Redwood City, CA, USA) was used for data acquisition and processing. The lower limit of quantification of soticlestat was $0.1 \mathrm{ng} / \mathrm{mL}$ and $0.5 \mathrm{ng} / \mathrm{g}$ in plasma and brain, respectively.

Measurement of 24S-hydroxycholesterol levels in brain. In this study, high-performance liquid chromatography (HPLC)-based assay was employed to improve the throughput of drug discovery campaign instead of LC-MS/MS analysis, which is used for plasma $24 S$-hydroxycholesterol analysis in clinical trials ${ }^{57}$. To determine the level of $24 S$-hydroxycholesterol in the brain, brain homogenate was prepared as described above. 24S-hydroxycholesterol was extracted from brain homogenate by mixing with equal volume (w/v) of $98 \%$ acetonitrile containing $2 \%$ methanol and $0.2 \%$ formic acid, and then centrifuged at $12,000 \mathrm{~g}$ for $15 \mathrm{~min}$ at room 
temperature. The supernatant was filtrated with a $0.45 \mu \mathrm{m}$ filter and measured by high-performance liquid chromatography (HPLC). A ready-to-use prepacked C18 column (Capcell Pak C18 MGII, $3 \mu \mathrm{m}, 3.0 \mathrm{~mm}$ inner diameter [ID] $\times 75 \mathrm{~mm}$ length, Shiseido, Kyoto, Japan) with a precolumn packed with the same material (silica gel) was used for separation. Diluted water with $0.1 \%$ trifluoroacetic acid (A) and methanol with $0.1 \%$ trifluoroacetic acid (B) were used for the chromatographic run. The composition of the mobile phase was changed according to the following time programme: $0-1 \mathrm{~min} 20 \%(\mathrm{~A})$ and $80 \%(\mathrm{~B}) ; 1-21 \mathrm{~min} 10 \%(\mathrm{~A})$ and $90 \%(\mathrm{~B}) ; 21-25 \mathrm{~min}$ $100 \%$ (B); and $25-30 \mathrm{~min} 100 \%$ (B). The flow rate was $0.5 \mathrm{~mL} / \mathrm{min}$. Peaks were detected by an ultraviolet (UV) detector at $210 \mathrm{~nm}$. The peak at the retention time of $13 \mathrm{~min}$ was extracted by fraction collector and confirmed as $24 S$-hydroxycholesterol by LC-MS/MS. The peak area was analysed by using the LabSolutions software version 5.57 (Shimadzu, Kyoto, Japan). The HPLC method estimate the baseline $24 S$-hydroxycholesterol at $30 \mu \mathrm{g} / \mathrm{mg}$ tissue, which roughly agree with that reported in literature. The $24 S$-hydroxycholesterol peak was not detected from brain samples derived from $\mathrm{CH} 24 \mathrm{H}-\mathrm{KO}$ mice, suggesting that the HPLC condition sufficiently separate $24 S$-hydroxycholesterol from other contaminants that would undermine the quantification (Supplementary Fig. S13).

Animal models. $\mathrm{CH} 24 \mathrm{H}-\mathrm{KO}$ mice were purchased (B6. 129S7-Cyp46a1Rus/J, Jackson Laboratory, Sacramento, CA, USA). APP/PS1-Tg mice were obtained by cross-breeding APP-SW mice (Tg2576) ${ }^{28}$ with PS$1 \mathrm{M} 146 \mathrm{~L}$ knock-in mice ${ }^{29}$. The female mice were maintained in house and used for the survival experiment at 7 weeks of age. The animals were housed at a temperature of $22{ }^{\circ} \mathrm{C} \pm 1{ }^{\circ} \mathrm{C}$ (mean \pm s.d.) with a $12 \mathrm{~h}$ light-dark cycle (lights on from 07:00 to 19:00) and allowed free access to food and water.

Survival observation of APP/PS1-Tg mice. The survival of 7-week-old APP/PS1-Tg mice was monitored for 8 weeks. Mice were orally treated with vehicle $(0.5 \%$ methyl cellulose, $n=30)$ or soticlestat at the dose of $10 \mathrm{mg} / \mathrm{kg}(\mathrm{n}=30)$ QD until they died.

Glutamate microdialysis. The APP/PS1-Tg mice treated with vehicle $(0.5 \%$ methyl cellulose; $\mathrm{n}=12)$ and those treated with soticlestat $(n=12)$ were subjected to the microdialysis study. Under pentobarbital-chlorohydrate anaesthesia, the guide cannula (AMUZA Inc, San Diego, CA, USA) was stereotactically implanted in the left hippocampus at the following coordinates (mm from bregma): A-3.1, L+2.8, V-2.0. One week after the surgery, a microdialysis probe (depth $4 \mathrm{~mm}$, length $2 \mathrm{~mm}$ ) was inserted through the guide cannula, and the hippocampus was continuously perfused with Ringer's solution $(147 \mathrm{mmol} / \mathrm{L}$ of $\mathrm{NaCl}, 4.03 \mathrm{mmol} / \mathrm{L} \mathrm{of} \mathrm{KCl}$ and $0.30 \mathrm{mmol} / \mathrm{L}$ of $\mathrm{CaCl}_{2}$ ) at a rate of $2 \mu \mathrm{L} / \mathrm{min}$ for $3 \mathrm{~h}$. The total sampling time was $130 \mathrm{~min}$, consisting of 13 samplings (10 min intervals each). The first sample $(0-10 \mathrm{~min})$ was not used for analysis because of injection noise. The next six samples (10-70 $\mathrm{min}$ ) were collected as a baseline. The perfusion fluid was then switched from normal Ringer's solution to the Ringer's solution containing $100 \mathrm{mmol} / \mathrm{L}$ of $\mathrm{KCl}$ with six subsequent samples (70-130 min) being collected. Analysis of dialysis samples was performed by reversed-phase HPLC operated by the PowerChrome software version 2.5.8 (eDAQ, Denistone East, Australia). The baseline glutamate level was calculated as an average concentration in the first $60 \mathrm{~min}$. The potassium-induced glutamate elevation was defined as the ratio of the maximum value to the baseline average.

Study approval. The animal experiments were approved by the Experimental Animal Care and Use Committee of Takeda Pharmaceutical Company Ltd and conducted in accordance with the guidelines. The animal care and use programme is accredited by the American Association for Accreditation of Laboratory Animal Care (AAALAC) International's Council on Accreditation. The AAALAC sets standards that call for the humane care and use of laboratory animals by enhancing animal well-being, improving the quality of research and advancing scientific knowledge relevant to humans and animals.

Statistical analysis. The statistical significance between two experimental groups was evaluated by Student's $\mathrm{t}$-test, with probability values $(P)$ less than $5 \%$ considered significant $\left({ }^{\star} P<0.05,{ }^{*} P<0.01\right)$. To evaluate dose dependency, one-tailed Williams' test was used and probability values less than $2.5 \%$ were considered significant $\left({ }^{\#} P<0.025\right)$.

\section{Data availability}

The data that support the findings of this study are available on request from the corresponding author (T.N.). The data are not publicly available due to Takeda Pharmaceuticals publication policy.

Received: 15 July 2020; Accepted: 23 September 2020

Published online: 13 October 2020

\section{References}

1. Pfrieger, F. W. Outsourcing in the brain: do neurons depend on cholesterol delivery by astrocytes?. BioEssays 25, 72-78 (2003).

2. Dietschy, J. M. \& Turley, S. D. Thematic review series: brain. Lipids Cholesterol metabolism in the central nervous system during early development and in the mature animal. J. Lipid Res. 45, 1375-1397 (2004).

3. Borroni, M. V., Valles, A. S. \& Barrantes, F. J. The lipid habitats of neurotransmitter receptors in brain. Biochem. Biophys. Acta. 1858, 2662-2670 (2016).

4. Bjorkhem, I. \& Meaney, S. Brain cholesterol: long secret life behind a barrier. Arterioscler. Thromb. Vasc. Biol. 24, 806-815 (2004).

5. Lund, E. G. et al. Knockout of the cholesterol 24-hydroxylase gene in mice reveals a brain-specific mechanism of cholesterol turnover. J. Biol. Chem. 278, 22980-22988 (2003). 
6. Xie, C., Lund, E. G., Turley, S. D., Russell, D. W. \& Dietschy, J. M. Quantitation of two pathways for cholesterol excretion from the brain in normal mice and mice with neurodegeneration. J. Lipid Res. 44, 1780-1789 (2003).

7. Leoni, V. Oxysterols as markers of neurological disease-a review. Scand. J. Clin. Lab. Invest. 69, 22-25 (2009).

8. Lund, E. G., Guileyardo, J. M. \& Russell, D. W. cDNA cloning of cholesterol 24-hydroxylase, a mediator of cholesterol homeostasis in the brain. Proc. Natl. Acad. Sci. USA 96, 7238-7243 (1999).

9. Bogdanovic, N. et al. On the turnover of brain cholesterol in patients with Alzheimer's disease. Abnormal induction of the cholesterol-catabolic enzyme CYP46 in glial cells. Neurosci. Lett. 314, 45-48 (2001).

10. Brown, J. 3rd. et al. Differential expression of cholesterol hydroxylases in Alzheimer's disease. J. Biol. Chem. 279, 34674-34681 (2004).

11. Meaney, S., Lutjohann, D., Diczfalusy, U. \& Bjorkhem, I. Formation of oxysterols from different pools of cholesterol as studied by stable isotope technique: cerebral origin of most circulating 24S-hydroxycholesterol in rats, but not in mice. Biochem. Biophys. Acta 1486, 293-298 (2000).

12. Bjorkhem, I. et al. Cholesterol homeostasis in human brain: turnover of 24S-hydroxycholesterol and evidence for a cerebral origin of most of this oxysterol in the circulation. J. Lipid Res. 39, 1594-1600 (1998).

13. Combarros, O., Infante, J., Llorca, J. \& Berciano, J. Genetic association of CYP46 and risk for Alzheimer's disease. Dement. Geriatr. Cogn. Disord. 18, 257-260 (2004).

14. Fourgeux, C. et al. Primary open-angle glaucoma: association with cholesterol 24S-hydroxylase (CYP46A1) gene polymorphism and plasma 24-hydroxycholesterol levels. Invest. Ophthalmol. Vis. Sci. 50, 5712-5717 (2009).

15. Boussicault, L. et al. CYP46A1, the rate-limiting enzyme for cholesterol degradation, is neuroprotective in Huntington's disease. Brain 139, 953-970 (2016).

16. Djelti, F. et al. CYP46A1 inhibition, brain cholesterol accumulation and neurodegeneration pave the way for Alzheimer's disease. Brain 138, 2383-2398 (2015).

17. Hudry, E. et al. Adeno-associated virus gene therapy with cholesterol 24-hydroxylase reduces the amyloid pathology before or after the onset of amyloid plaques in mouse models of Alzheimer's disease. Mol. Ther. 18, 44-53 (2010).

18. Mast, N. et al. Cholesterol-metabolizing enzyme cytochrome P450 46Al as a pharmacologic target for Alzheimer's disease. Neuropharmacology 123, 465-476 (2017).

19. Mast, N., Verwilst, P., Wilkey, C. J., Guengerich, F. P. \& Pikuleva, I. A. In vitro activation of cytochrome P450 46A1 (CYP46A1) by efavirenz-related compounds. J. Med. Chem. 63, 6477-6488 (2020).

20. Petrov, A. M. et al. CYP46A1 activation by efavirenz leads to behavioral improvement without significant changes in amyloid plaque load in the brain of 5XFAD mice. Neurotherapeutics 16, 710-724 (2019).

21. Paul, S. M. et al. The major brain cholesterol metabolite 24(S)-hydroxycholesterol is a potent allosteric modulator of $N$-methylD-aspartate receptors. J. Neurosci. 33, 17290-17300 (2013).

22. Li, Y., Yang, X., Ma, C., Qiao, J. \& Zhang, C. Necroptosis contributes to the NMDA-induced excitotoxicity in rat's cultured cortical neurons. Neurosci. Lett. 447, 120-123 (2008).

23. Noguchi, N., Saito, Y. \& Urano, Y. Diverse functions of 24(S)-hydroxycholesterol in the brain. Biochem. Biophys. Res. Commun. 446, 692-696 (2014).

24. Nury, T. et al. Induction of oxiapoptophagy on $158 \mathrm{~N}$ murine oligodendrocytes treated by 7 -ketocholesterol-, 7beta-hydroxycholesterol-, or 24(S)-hydroxycholesterol: Protective effects of alpha-tocopherol and docosahexaenoic acid (DHA; C22:6 n-3). Steroids 99, 194-203 (2015).

25. Alexandrov, P., Cui, J. G., Zhao, Y. \& Lukiw, W. J. 24S-hydroxycholesterol induces inflammatory gene expression in primary human neural cells. Neuroreport 16, 909-913 (2005).

26. Mast, N., Zheng, W., Stout, C. D. \& Pikuleva, I. A. Binding of a cyano- and fluoro-containing drug bicalutamide to cytochrome P450 46A1: unusual features and spectral response. J. Biol. Chem. 288, 4613-4624 (2013).

27. Shafaati, M. et al. The antifungal drug voriconazole is an efficient inhibitor of brain cholesterol 24S-hydroxylase in vitro and in vivo. J. Lipid Res. 51, 318-323 (2010).

28. Holcomb, L. et al. Accelerated Alzheimer-type phenotype in transgenic mice carrying both mutant amyloid precursor protein and presenilin 1 transgenes. Nat. Med. 4, 97-100 (1998).

29. Kang, D. E. et al. Presenilin 1 facilitates the constitutive turnover of beta-catenin: differential activity of Alzheimer's disease-linked PS1 mutants in the beta-catenin-signaling pathway. J. Neurosci. 19, 4229-4237 (1999).

30. Dickey, C. A. et al. Dysregulation of $\mathrm{Na}^{+} / \mathrm{K}^{+}$ATPase by amyloid in APP + PS1 transgenic mice. BMC Neurosci. 6, 7 (2005).

31. Sierksma, A. S. et al. Fluoxetine treatment induces seizure behavior and premature death in APPswe/PS1dE9 mice. JAD 51, 677-682 (2016).

32. Halford, R. W. \& Russell, D. W. Reduction of cholesterol synthesis in the mouse brain does not affect amyloid formation in Alzheimer's disease, but does extend lifespan. Proc. Natl. Acad. Sci. USA 106, 3502-3506 (2009).

33. Yutuc, E. et al. Localization of sterols and oxysterols in mouse brain reveals distinct spatial cholesterol metabolism. Proc. Natl. Acad. Sci. USA 117, 5749-5760 (2020).

34. Ramirez, D. M., Andersson, S. \& Russell, D. W. Neuronal expression and subcellular localization of cholesterol 24-hydroxylase in the mouse brain. J. Comp. Neurol. 507, 1676-1693 (2008).

35. Oyelami, T. et al. Age-dependent concomitant changes in synaptic dysfunction and GABAergic pathway in the APP/PS1 mouse model. Acta Neurobiol. Exp. 76, 282-293 (2016).

36. Schmid, L. C. et al. Dysfunction of somatostatin-positive interneurons associated with memory deficits in an Alzheimer's disease model. Neuron 92, 114-125 (2016).

37. Minkeviciene, R. et al. Amyloid beta-induced neuronal hyperexcitability triggers progressive epilepsy. J. Neurosci. 29, 3453-3462 (2009).

38. Tian, G., Kong, Q., Lai, L., Ray-Chaudhury, A. \& Lin, C. L. Increased expression of cholesterol 24S-hydroxylase results in disruption of glial glutamate transporter EAAT2 association with lipid rafts: a potential role in Alzheimer's disease. J. Neurochem. 113, 978-989 (2010).

39. Minkeviciene, R. et al. Age-related decrease in stimulated glutamate release and vesicular glutamate transporters in APP/PS1 transgenic and wild-type mice. J. Neurochem. 105, 584-594 (2008).

40. Sodero, A. O. et al. Cholesterol loss during glutamate-mediated excitotoxicity. EMBO J. 31, 1764-1773 (2012).

41. Nieweg, K., Schaller, H. \& Pfrieger, F. W. Marked differences in cholesterol synthesis between neurons and glial cells from postnatal rats. J. Neurochem. 109, 125-134 (2009).

42. Petrov, A. M. \& Pikuleva, I. A. Cholesterol 24-hydroxylation by CYP46A1: benefits of modulation for brain diseases. Neurotherapeutics 16, 635-648 (2019).

43. Bialer, M. et al. Progress report on new antiepileptic drugs: a summary of the Fourteenth Eilat Conference on New Antiepileptic Drugs and Devices (EILAT XIV) I Drugs in preclinical and early clinical development. Epilepsia 59, 1811-1841 (2018).

44. Zullo, J. M. et al. Regulation of lifespan by neural excitation and REST. Nature 574, 359-364 (2019).

45. Holt, R. L., Arehart, E., Hunanyan, A., Fainberg, N. A. \& Mikati, M. A. Pediatric sudden unexpected death in epilepsy: what have we learned from animal and human studies, and can we prevent it?. Sem. Pediatr. Neurol. 23, 127-133 (2016).

46. Bagnall, R. D., Crompton, D. E. \& Semsarian, C. Genetic basis of sudden unexpected death in epilepsy. Front. Neurol. 8, 348 (2017). 
47. Kotti, T. J., Ramirez, D. M., Pfeiffer, B. E., Huber, K. M. \& Russell, D. W. Brain cholesterol turnover required for geranylgeraniol production and learning in mice. Proc. Natl. Acad. Sci. USA 103, 3869-3874 (2006).

48. Petrov, A. M., Mast, N., Li, Y. \& Pikuleva, I. A. The key genes, phosphoproteins, processes, and pathways affected by efavirenzactivated CYP46A1 in the amyloid-decreasing paradigm of efavirenz treatment. FASEB J. 33, 8782-8798 (2019).

49. Mast, N. et al. In vitro cytochrome P450 46A1 (CYP46A1) activation by neuroactive compounds. J. Biol. Chem. 292, 12934-12946 (2017).

50. Massey, J. B. \& Pownall, H. J. Structures of biologically active oxysterols determine their differential effects on phospholipid membranes. Biochemistry 45, 10747-10758 (2006).

51. Pfrieger, F. W. Cholesterol homeostasis and function in neurons of the central nervous system. CMLS 60, 1158-1171 (2003).

52. Pfrieger, F. W. \& Ungerer, N. Cholesterol metabolism in neurons and astrocytes. Prog. Lipid Res. 50, 357-371 (2011).

53. Vo, D. K., Urano, Y., Takabe, W., Saito, Y. \& Noguchi, N. 24(S)-Hydroxycholesterol induces RIPK1-dependent but MLKL-independent cell death in the absence of caspase-8. Steroids 99, 230-237 (2015).

54. Chali, F. et al. Inhibiting cholesterol degradation induces neuronal sclerosis and epileptic activity in mouse hippocampus. Eur. J. Neurosci. 41, 1345-1355 (2015).

55. Liljequist, S., Ossowska, K., Grabowska-Anden, M. \& Anden, N. E. Effect of the NMDA receptor antagonist, MK-801, on locomotor activity and on the metabolism of dopamine in various brain areas of mice. Eur. J. Pharmacol. 195, 55-61 (1991).

56. Keith-Franklin, G. P. The Mouse Brain in Stereotaxic Coordinates, Compact (Academic Press, New York, 2008).

57. Sugimoto, H., Kakehi, M., Satomi, Y., Kamiguchi, H. \& Jinno, F. Method development for the determination of 24S-hydroxycholesterol in human plasma without derivatization by high-performance liquid chromatography with tandem mass spectrometry in atmospheric pressure chemical ionization mode. J. Sep. Sci. 38, 3516-3524 (2015).

\section{Acknowledgements}

We thank Makoto Furusawa, Shigeru Morita, Keisuke Hirai, Takeo Wada, Thomas Misko and Leslie Shinobu for their advice on experiments, Brett Abrahams and Melanie von Schimmelmann for comments on the manuscript, and Doug Dougan and Ling Quin for medicinal chemistry support, and Megumi Hirayama and Hidenori Kamiguchi for mass spectrometry data acquisition and analysis, Masahiko Hattori for immunohistochemistry.

\section{Author contributions}

T.N., S.K., M.M., T. Ko and T. Ku participated in research design. T.N., M.M., S.W., S.H., S.K., J.Y., E.W., T.I., M.Y., H.K.A., W.F., S.F., E.S., M.O. and T. Ku conducted experiments and performed data analysis. T.N., S.K., M.J.D. and T. Ko wrote the manuscript with input from all authors.

\section{Competing interests}

All authors, with the exception of M.J.D., are either current or former employees of Takeda Pharmaceutical Company Ltd. M.J.D. is the founder of Ovid Therapeutics Inc.

\section{Additional information}

Supplementary information is available for this paper at https://doi.org/10.1038/s41598-020-74036-6.

Correspondence and requests for materials should be addressed to T.N.

Reprints and permissions information is available at www.nature.com/reprints.

Publisher's note Springer Nature remains neutral with regard to jurisdictional claims in published maps and institutional affiliations.

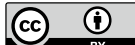

Open Access This article is licensed under a Creative Commons Attribution 4.0 International License, which permits use, sharing, adaptation, distribution and reproduction in any medium or format, as long as you give appropriate credit to the original author(s) and the source, provide a link to the Creative Commons licence, and indicate if changes were made. The images or other third party material in this article are included in the article's Creative Commons licence, unless indicated otherwise in a credit line to the material. If material is not included in the article's Creative Commons licence and your intended use is not permitted by statutory regulation or exceeds the permitted use, you will need to obtain permission directly from the copyright holder. To view a copy of this licence, visit http://creativecommons.org/licenses/by/4.0/.

(C) The Author(s) 2020 